\title{
Inhibition of NMDA receptors by agmatine is followed by GABA/glutamate balance in benzodiazepine withdrawal syndrome
}

\author{
Hira Rafi, Hamna Rafiq and Muhammad Farhan
}

\begin{abstract}
Background: Drug withdrawal syndrome occurs due to abrupt cessation of an addictive substance. Dependence to diazepam can be manifested by withdrawal syndrome which may include symptoms such as irritability, psychosis, sleep disturbance, seizures, mood disturbance, and anxiety. Studies have described the therapeutic role of agmatine in various neurological disorders such as depressive mood, learning deficits, anxiety, memory impairment, and psychosis. Various studies have also validated agmatine as a putant neuromodulator and revealed its mechanism of action with other neurotransmitters. The study was designed to reveal the potentials of agmatine in benzodiazepine withdrawal syndrome by maintaining GABA/glutamate balance. The study aimed to determine the underlying mechanism of action of agmatine at synaptic level using behavioral and biochemical evaluations.

Results: Agmatine significantly enhanced locomotion in open filed test and decreased anxiety as observed in elevated plus maze test $(p<0.01)$. Agmatine also reduced withdrawal symptoms scores along with compulsive behaviors in marble burying test and improved muscular strength by decreasing latency to fall in inverted screen test $(p<0.01)$. Moreover, agmatine established GABA/glutamate balance by increasing GABA levels and decreased glutamate concentration significantly $(p<0.01)$.

Conclusion: The present study reveals the possible mechanism of action of agmatine on NMDA receptor at GABA interneurons and glutamate post synaptic neuron that may lead to GABA/glutamate balance during withdrawal syndrome.
\end{abstract}

Keywords: Agmatine, GABA, Glutamate, NMDA, Diazepam withdrawal syndrome

\section{Background}

Drug withdrawal symptoms are often considered disease state in medical practices. Discontinuation of various drugs or addiction of any interconnecting substance determines the withdrawal syndrome accurately. Withdrawal symptoms may include depression, anxiety, tremors, agitation, blurred vision, and insomnia.

Benzodiazepine withdrawal syndrome can be mild or severe [6]. Potent benzodiazepine, chronic or high dose intake, anxiety, or neuroticism results in severity of the syndrome $[6,27]$. Benzodiazepine tolerance is produced

\footnotetext{
*Correspondence: hira.rafi@hotmail.com

Department of Biochemistry, University of Karachi, Karachi 75270, Pakistan
}

by neuroadpative routes including sensitization of glutamatergic receptors and desensitization of g-aminobutyric acid (GABA) receptors. Once tolerance has developed, abrupt cessation of benzodiazepine produces the neurological consequences of withdrawal. This includes the reduced functions of GABA and hyperactivity of glutamate that leads to various benzodiazepine symptoms. Receptors modifications during tolerance might be slow and reverse at different rates. This possibly explains the difference of development and duration of symptoms along with prolongs nature of benzodiazepine withdrawal [6]. Agmatine selectively antagonize the glutamate receptor channels of NMDA [37, 39] and inhibits NOS. Various studies have demonstrated that exogenous agmatine
Springer Open (c) The Author(s). 2021 Open Access This article is licensed under a Creative Commons Attribution 4.0 International License, which permits use, sharing, adaptation, distribution and reproduction in any medium or format, as long as you give appropriate credit to the original author(s) and the source, provide a link to the Creative Commons licence, and indicate if changes were made. The images or other third party material in this article are included in the article's Creative Commons licence, unless indicated otherwise in a credit line to the material. If material is not included in the article's Creative Commons licence and your intended use is not permitted by statutory regulation or exceeds the permitted use, you will need to obtain permission directly from the copyright holder. To view a copy of this licence, visit http://creativecommons.org/licenses/by/4.0/. 
administration protect cells against cellular damages caused by glutamate and NMDA [15]. Agmatine also reverses or averts glutamatergic pathways dependent biological mechanisms in CNS [32]. $\alpha 2$-Adrenoceptor increases the GABA release in various brain regions [1]. $\alpha 2$-Adrenoceptor and GABA receptors physiological interaction in CNS has been accepted widely and $\alpha 2$ adrenoceptor expression is confirmed in GABAergic presynaptic nerve terminal [22]. The functional interaction of agmatine and $\alpha 2$-adrenoceptors has important inhibitory effects on nicotine induced behavioral sensitization [21] and potentiates conditioned place preference, analgesia and anticonvulsant induced by morphine [34].

The study was designed to determine the potentials of agmatine in benzodiazepine withdrawal syndrome by maintaining GABA/glutamate balance. The study aimed to reveal the underlying mechanism of action of agmatine at synaptic level. Potential mechanism of action of agmatine against withdrawal syndrome is given in Fig. 1.

\section{Methods}

\subsection{Animals and drug administration}

Male albino Wistar rats, approximately 6-8 months old and weighing between 120-180 g were purchased from Dow University of Health and Sciences, Karachi. All experiments were approved by the Institutional Advanced Studies and Research Board (BASR/03367/Sc.) and performed in strict accordance with National Institute of Health Guide for Care and Use of Laboratory Animals (NIH Publication no. 85-23, revised 2011). Animals were housed separately under controlled conditions of 12:12 h light /dark cycle, temperature $25 \pm 1{ }^{\circ} \mathrm{C}$ and free accesses to water and food for 3 days for acclimatization before the experiments. Valium (diazepam) ampoules 10

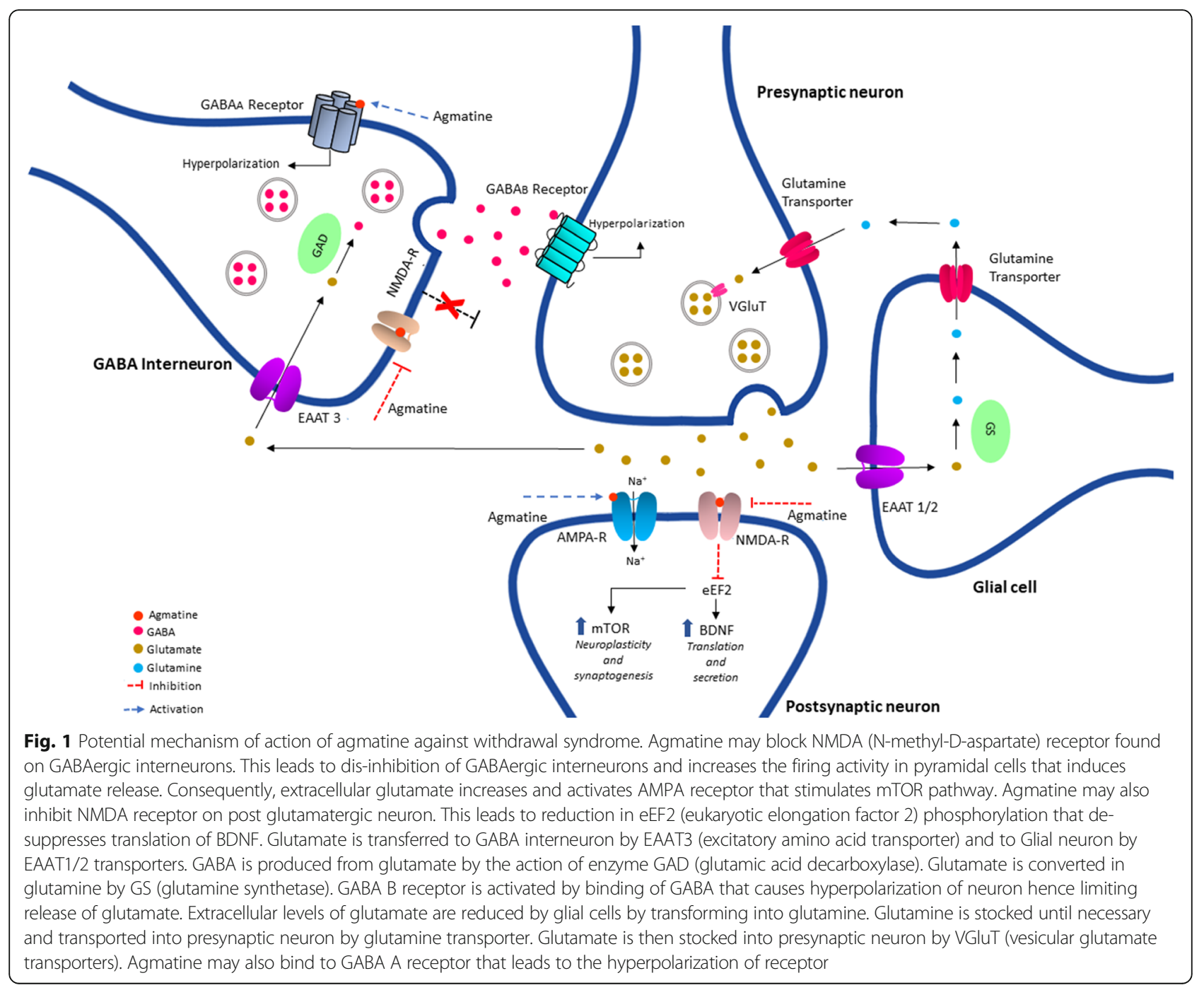


$\mathrm{mg} / 2 \mathrm{ml}$ from Roche was dissolved in $0.9 \% \mathrm{NaCl}$ and given intraperitoneally agmatine was purchased from Sigma-Aldrich and was administered orally by stainless steel oral gavage.

\subsection{Experimental protocol}

Rats $(\mathrm{n}=48)$ were divided randomly into control and test $(\mathrm{n}=24)$ each groups. Diazepam $(5 \mathrm{mg} / \mathrm{Kg})$ was administered daily for 21 days while controls were treated with water only. Diazepam was abruptly ceased on the 22nd day of drug administration and $12 \mathrm{~h}$ after drug withdrawal, controls and diazepampretreated animals were further divided into two groups $(\mathrm{n}=12)$ each that received (a) water and $(\mathrm{b})$ agmatine (100 mg/Kg p.o.). Agmatine $(100 \mathrm{mg} / \mathrm{Kg}$ ) was dissolved in distilled water and was given daily for the next 7 days of withdrawal. Behaviors were analyzed in various paradigms on the 1st and 7th day of withdrawal. Withdrawal symptoms were assessed after 12, 24, 48, 96, and $168 \mathrm{~h}$ of withdrawal. Rats were decapitated humanly immediately after last behavioral tests to estimate GABA and glutamate levels in brain samples.

\subsection{Behavioral estimations}

\subsubsection{Open field activity}

Open field test is an uncomplicated and simple assessment of behaviors that require no animal training. It has been most widely used as assessment of locomotive behavior and exploration in rodents [36]. The apparatus consisted of $76 \times 76-\mathrm{cm}$ square area with $42-\mathrm{cm}$-high opaque plastic walls. The floor was divided into 25 equal squares. Rat was placed in the center box of arena and exploration; anxiety and ambulation were observed in 5min examination.

\subsubsection{Elevated plus maze}

EPM possess great possible diversity of application including screening of newly developed anxiety treatment agent, anxiolytic and anxiogenic effects of drugs. The apparatus consists of plus shaped four arms in which two arms are open $(50 \times 10 \mathrm{~cm})$ and two closed arms $(50 \times 20 \mathrm{~cm})$ with $15-\mathrm{cm}$-high opaque walls. Open arms edges were $25-\mathrm{cm}$ high to avoid fall of rat. The maze was elevated $100 \mathrm{~cm}$ above the ground. Each rat is positioned at the center of maze facing enclosed arm. Time spent and entries in open arms were observed in 5-min test period [29].

\subsubsection{Withdrawal symptoms score}

A valid and reliable rating scale is used to assess withdrawal symptoms in rodents. The rating scale enables scientists to effectively manage withdrawal syndrome as it facilitates to describe severity and progress of the disease in a well-defined way [38]. During each withdrawal test session, a single rat is placed in an operant box and withdrawal scorings were began immediately. Each rat received 10-min observation periods in each test. Along with tabulation individual withdrawal behavior of rats, a

Table 1 Diazepam withdrawal scoring

\begin{tabular}{|c|c|}
\hline Activity & Score \\
\hline \multicolumn{2}{|l|}{ Vocalization } \\
\hline No abnormality & 0 \\
\hline Mild & 1 \\
\hline Intermediate & 2 \\
\hline Severe & 3 \\
\hline \multicolumn{2}{|l|}{ Agitation } \\
\hline No agitation & 0 \\
\hline Rats showing irritable agitation & 1 \\
\hline Handling vocalization/very aggressive & 2 \\
\hline Spontaneous vocalization and very aggressive & 3 \\
\hline \multicolumn{2}{|l|}{ Ear-twitching (shaking or trembling of ear) } \\
\hline Absence & 0 \\
\hline Mild & 1 \\
\hline Intermediate & 2 \\
\hline Severe & 3 \\
\hline \multicolumn{2}{|l|}{ Fascicular twitch (shaking or trembling of nape) } \\
\hline Absence & 0 \\
\hline Mild & 1 \\
\hline Intermediate & 2 \\
\hline Severe & 3 \\
\hline \multicolumn{2}{|l|}{ Tremors } \\
\hline No tremor & 0 \\
\hline Normal body vibrations & 1 \\
\hline Tremor and rigidity & 2 \\
\hline Severe shivering or shaking & 3 \\
\hline \multicolumn{2}{|l|}{ Handling-induced clonic convulsion } \\
\hline Absence & 0 \\
\hline Rats showing only wild running & 1 \\
\hline Rats showing tonic-clonic seizure & 2 \\
\hline Rats showing severe tonic-clonic seizure $190 \mathrm{~S}$ & 3 \\
\hline \multicolumn{2}{|l|}{ Spontaneous clonic convulsion } \\
\hline Absence & 0 \\
\hline Rats showing only wild running & 1 \\
\hline Rats showing tonic-clonic seizure & 2 \\
\hline Rats showing severe tonic-clonic seizure $190 \mathrm{~S}$ & 3 \\
\hline \multicolumn{2}{|l|}{ Abnormal posture } \\
\hline Normal posture & 0 \\
\hline Mild head-down, back-hunched & 1 \\
\hline Moderate head-down, back-hunched & 2 \\
\hline Prominent head-down, back-hunched & 3 \\
\hline
\end{tabular}


cumulative score was computed of all withdrawal behaviors. Different behaviors given in Table 1 were evaluated in diazepam withdrawal groups of animals.

\subsubsection{Marble burying test}

The marble burying test is widely used to explore obsessive-compulsive or repetitive-like behaviors and anxiety in rodents [2]. Defensive burying is known as a typical rodent behavior in which animal mess up saw dust vigorously with their forepaw in treading like movements and their heads in shoveling movements directed towards noxious stimuli [11]. Twenty glass marbles were placed in a cage having sawdust. The marbles were positioned in a regular grid pattern and rats were allowed to explore the cage for $15 \mathrm{~min}$. The total number of marble buried in bedding is counted. The percentage of marbles buried under the saw dust was the main outcome.

\section{a}

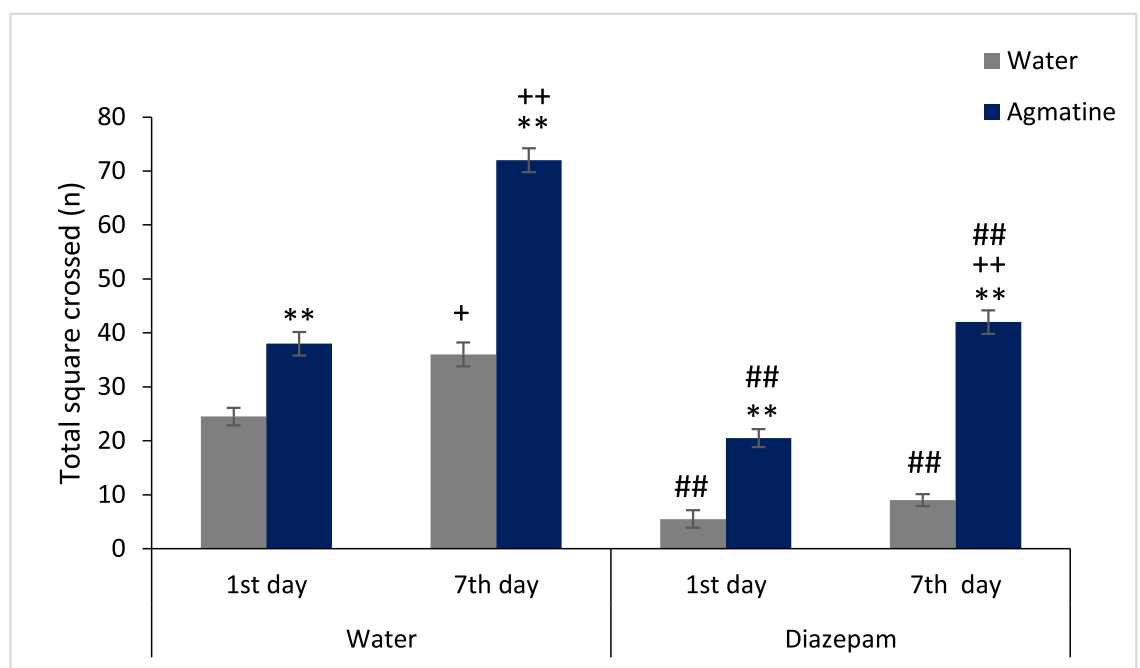

b

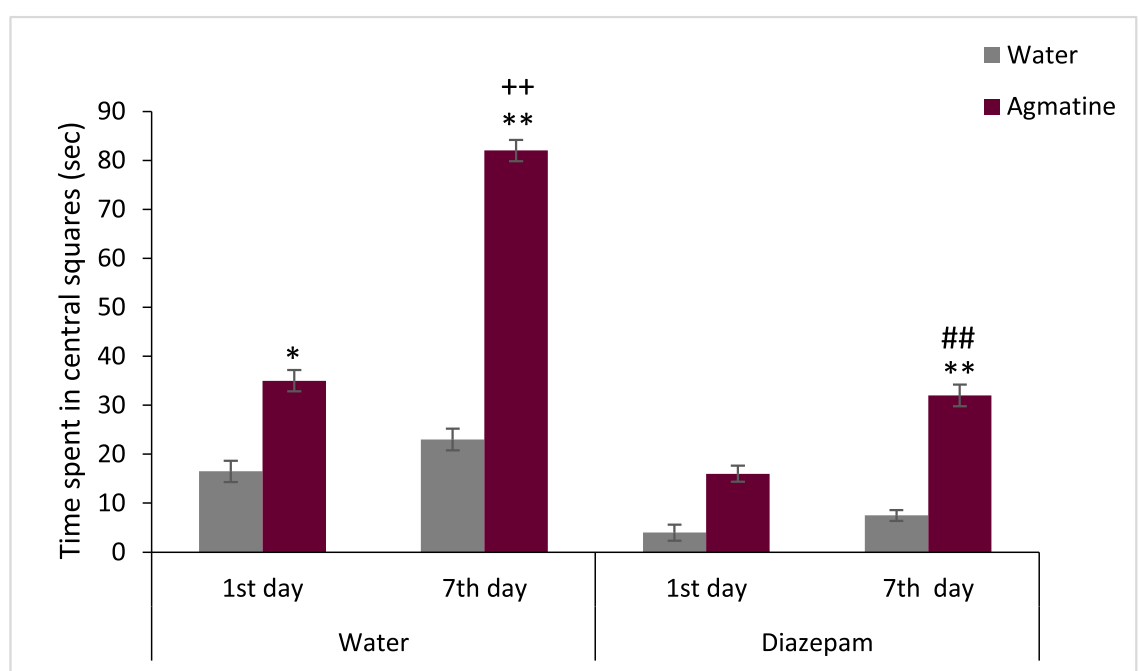

Fig. 2 a Open field test (total square crossed): Values are expressed as means $\pm S D(n=12)$. Significant differences by Newman-Keuls test: ${ }^{* *} p<0.01$, ${ }^{*} p<0.05$ from control group to agmatine-treated groups. ${ }^{++} p<0.01,{ }^{+} p<0.05$ from the 1 st day administration of water and agmatine. ${ }^{\# \#} p<0.01,{ }^{\#} p$ $<0.05$ from water-pretreated animals to respective withdrawal animals following II-way ANOVA. b Open field test (time spent in central squares): Values are expressed as means \pm SD $(n=12)$. Significant differences by Newman-Keuls test: ${ }^{* *} p<0.01,{ }^{*} p<0.05$ from control group to agmatinetreated groups. ${ }^{++} p<0.01,{ }^{+} p<0.05$ from the 1 st day administration of water and agmatine. ${ }^{\# \#} p<0.01,{ }^{\#} p<0.05$ from water-pretreated animals to respective withdrawal animals following II-way ANOVA 


\subsubsection{Inverted screen test}

In 1964, Kondziela proposed the inverted screen test for monitoring all four limbs muscular strength [19]. The test is used to assess rodents with neuromuscular disorders in order to monitor motor coordination and neuromuscular impairment. Most rodents are enthusiastic to perform the test as their natural behaviors do not want these animals to fall off the screen. In this study, untrained rats were placed on top of a cage cover. The screen was then inverted $180^{\circ}$ so that rat were on the bottom of the metal cover. The latency to fall off was recorded over a 1-min testing session.

\subsection{Biochemical estimations}

2.4.1 Estimation of GABA levels in brain samples

GABA content in whole brain samples was analyzed according to the method of Lowe and his coworkers [23]. Brain homogenates $(10 \% \mathrm{w} / \mathrm{v})$ were prepared by using 50 $\mathrm{mM}$ phosphate buffer at $\mathrm{pH}$ 7.0. The homogenates were de-proteinized by adding $5 \mathrm{ml}$ of chilled trichloroacetic

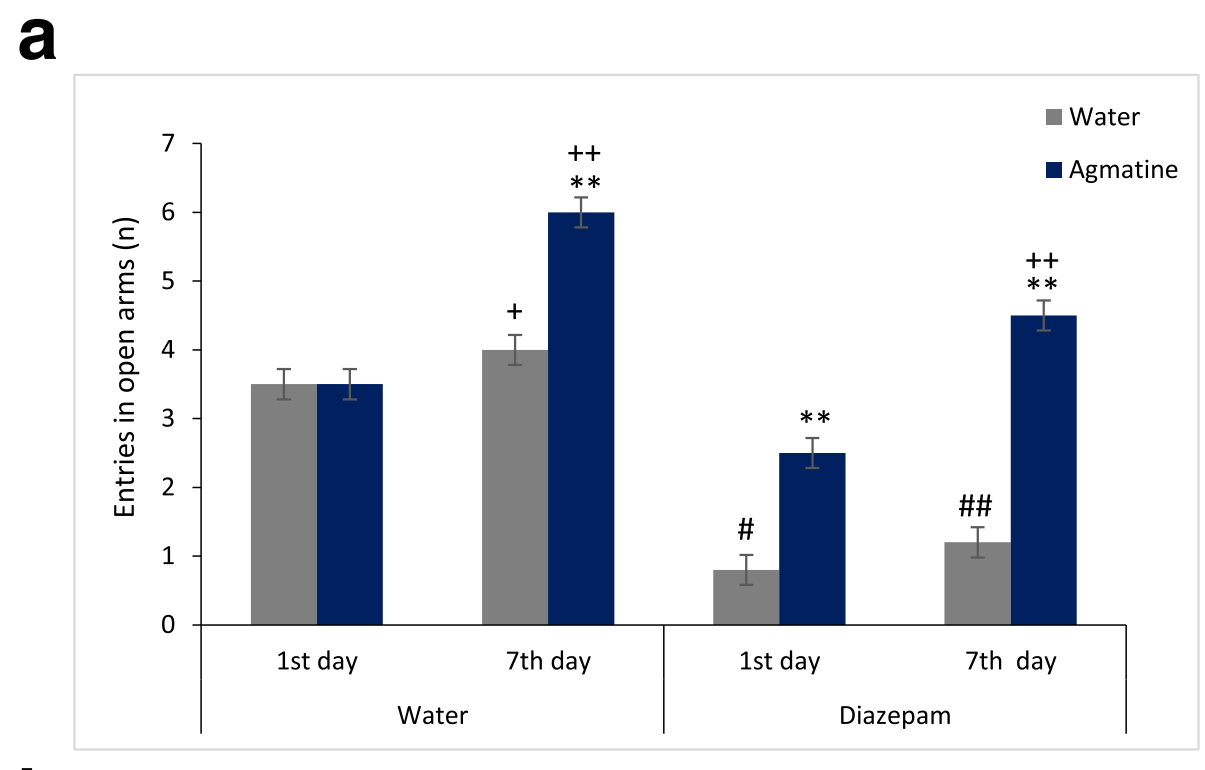

b

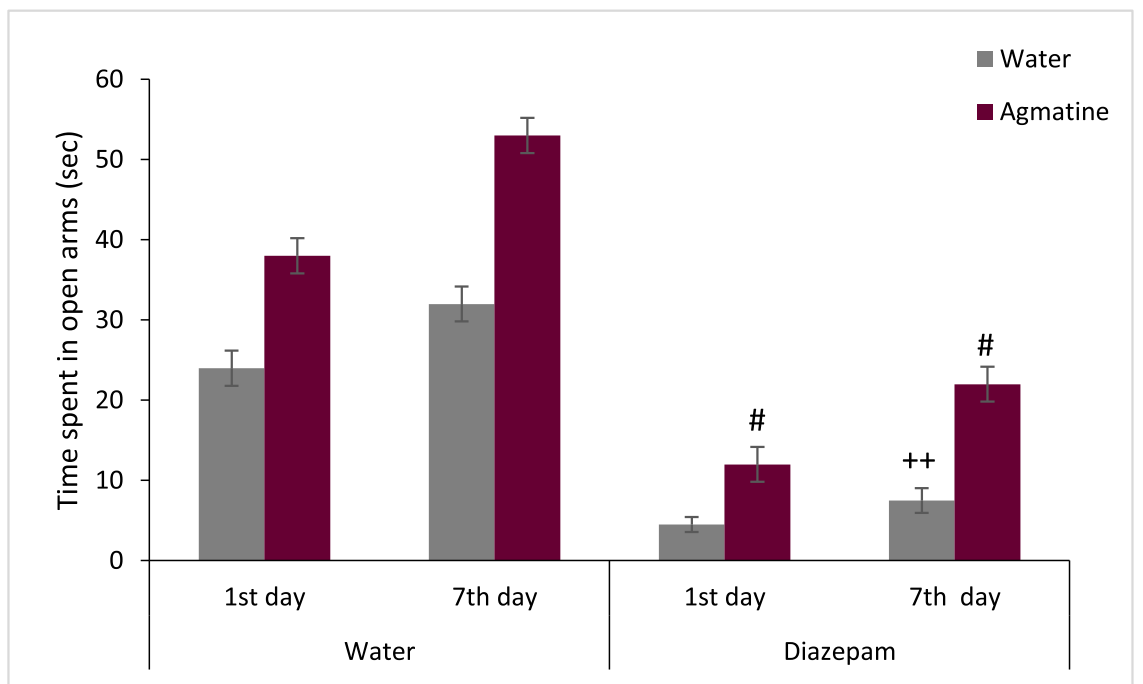

Fig. 3 a Elevated plus maze test (entries in open arms): Values are expressed as means $\pm S D(n=12)$. Significant differences by Newman-Keuls test: ${ }^{* *} p<0.01,{ }^{*} p<0.05$ from control group to agmatine-treated groups. ${ }^{++} p<0.01,{ }^{+} p<0.05$ from the 1 st day administration of water and agmatine. ${ }^{\# \#} p<0.01,{ }^{\#} p<0.05$ from water-pretreated animals to respective withdrawal animals following II-way ANOVA. b Elevated plus maze test (time spent in open arms): Values are expressed as means \pm SD $(n=12)$. Significant differences by Newman-Keuls test: ${ }^{* *} p<0.01,{ }^{*} p<0.05$ from control group to agmatine-treated groups. ${ }^{++} p<0.01,{ }^{+} p<0.05$ from the 1 st day administration of water and agmatine. ${ }^{\# \#} p<0.01,{ }^{\#} p<$ 0.05 from water-pretreated animals to respective withdrawal animals following II-way ANOVA 
acid $(10 \% \mathrm{w} / \mathrm{v})$. Homogenates were than centrifuged at 10 , $000 \mathrm{rpm}$ at $0{ }^{\circ} \mathrm{C}$ for $10 \mathrm{~min}$ to obtain cell free supernatant. One hundred microliters of supernatant was mixed with $0.2 \mathrm{ml}$ of $14 \mathrm{mM}$ ninhydrin in $0.5 \mathrm{M}$ carbonate-bicarbonate buffer. Gaba standards were prepared from 0.2, 0.4, $0.6,0.8$, and $1.0 \mu \mathrm{g} / \mathrm{ml}$ each in ice cold TCA solution $(10 \%$ $\mathrm{w} / \mathrm{v})$. The test tube was heated in water bath at $60{ }^{\circ} \mathrm{C}$ for $30 \mathrm{~min}$. After $30 \mathrm{~min}$, tube was cooled at room temperature and treated with $5 \mathrm{ml}$ of freshly prepared copper tartrate reagent. The solution was than vortexed and incubated at $25{ }^{\circ} \mathrm{C}$ for $15 \mathrm{~min}$. Fluorescence was recorded at $\lambda \operatorname{Ex} 377 \mathrm{~nm} / \lambda \operatorname{Em} 451 \mathrm{~nm}$ against blank. The
GABA content was calculated using standard curve and presented as $\mu \mathrm{mol} / \mathrm{g}$ of brain tissue.

\subsubsection{Estimation of glutamate levels in brain samples}

Glutamate concentration in brain sample was determined by the method described by [7]. Brain sample was weighed and homogenized with 2 parts of perchloric acid $1 \mathrm{M}, 70 \% \mathrm{v} / \mathrm{v}$ by weight, and centrifuged at 3000 rpm for $10 \mathrm{~min}$. Supernatant was taken for further investigation. Three milliliters of supernatant fluid was adjusted with $1.93 \mathrm{M}$ phosphate solution till the $\mathrm{pH}$ reached 9. The solution was allowed to stand in an ice
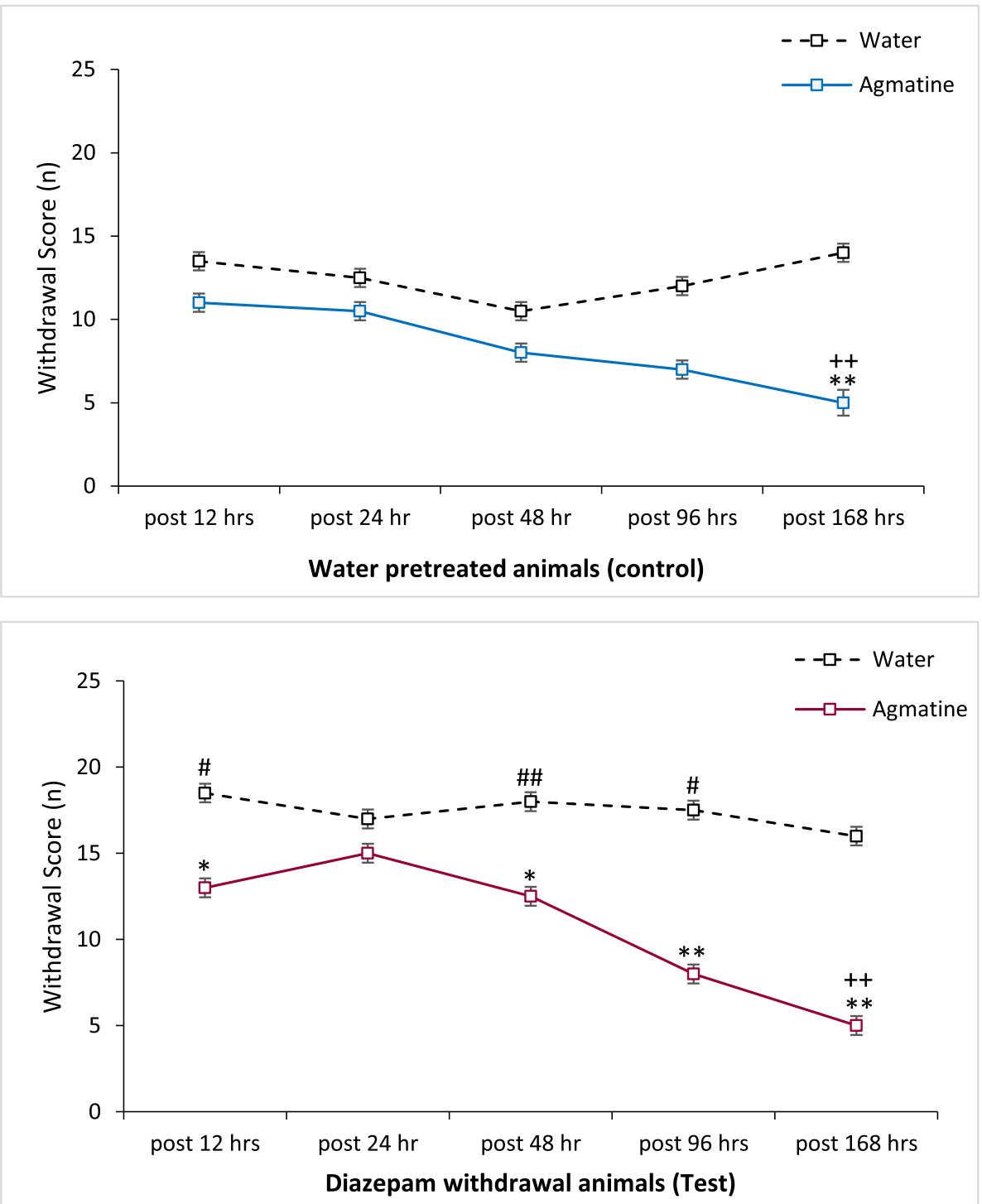

Fig. 4 Withdrawal symptoms score: Values are expressed as means $\pm \mathrm{SD}(\mathrm{n}=12)$. Significant differences by Newman-Keuls test: ${ }^{* *} p<0.01$, ${ }^{*} p<$ 0.05 from control group to agmatine-treated groups. ${ }^{++} p<0.01,{ }^{+} p<0.05$ from the 1 st day administration of water and agmatine. ${ }^{\# \#} p<0.01,{ }^{\#} p$ $<0.05$ from water-pretreated animals to respective withdrawal animals following II-way ANOVA 
bath for $10 \mathrm{~min}$ and filtered by using fluted filter paper. Absorbance was measured by spectrophotometer at 340 $\mathrm{nm}$. Blank was prepared containing water instead of sample. Glutamate level was expressed against blank as $\mu \mathrm{mol} / \mathrm{g}$ of tissue.

\subsection{Statistical analysis}

Behaviors results obtained were analyzed by II-way ANOVA (repeated measure designs) SPSS version 20 followed by Newman-Keuls post hoc test. Biochemical estimations were assessed by I-way ANOVA by Tukey's post hoc analysis. Correlation between GABA/glutamate, withdrawal scores/GABA, and withdrawal scores/glutamate levels were analyzed by Pearson correlation test. Statistical significance was considered $p<0.05$. Data are described as means $\pm \mathrm{SD}$.

\section{Results}

\subsection{Open field test}

\subsubsection{Total square crossed}

Data in Fig. 2a was analyzed by II-way ANOVA that explained the significant effects of days $(\mathrm{F}(1,55)=242.413, p<$ $0.05)$, days $\times$ drugs $(\mathrm{F}(3,55)=73.552, p<0.01)$, days $\times$ treatment $(\mathrm{F}(1,55)=14.644, p<0.25)$, drugs $(\mathrm{F}(3,55)=34.082$, $p<0.01)$, and treatment $(\mathrm{F}(1,55)=76.117, p<0.10)$. A significant increase in total square crossed was observed after the 1st and 7th administration of agmatine $(p<0.01)$ when compared with water controls. Increased square crossings were observed after one week in water $(p<0.05)$ and agmatine $(p<0.01)$ treated animals in water-pretreated control, while agmatine increased square crossings after the 7th $(p<$ $0.01)$ day in withdrawal animals. Agmatine $(p<0.01)$ also increased total square crossed after 7 days administration in withdrawal animals. Decreased square crossed was observed in water- and agmatine-treated animals after the 1st and 7th

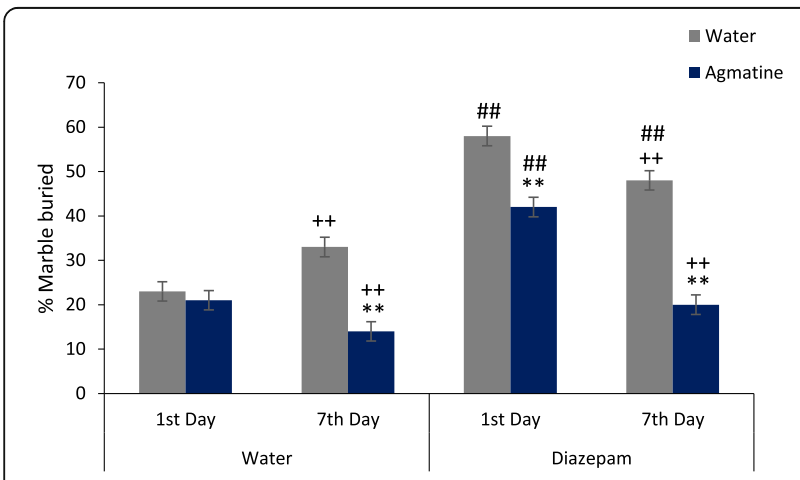

Fig. 5 Marble burying test: Values are expressed as means \pm SD ( $n=$ 12). Significant differences by Newman-Keuls test: ${ }^{* *} p<0.01$ from control group to agmatine-treated groups. ${ }^{++} p<0.01,{ }^{+} p<0.05$ from the 1st day administration of water and agmatine. ${ }^{\# \#} p<0.01$ from water-pretreated animals to respective withdrawal animals following II-way ANOVA

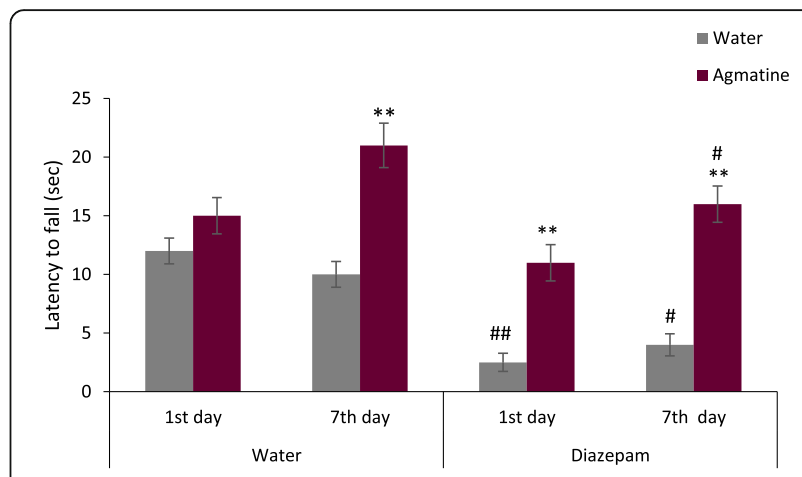

Fig. 6 Inverted screen test: Values are expressed as means \pm SD $(n=$ 12). Significant differences by Newman-Keuls test: ${ }^{* *} p<0.01$ from control group to agmatine-treated groups. ${ }^{\# \#} p<0.01,{ }^{\#} p<0.05$ from water-pretreated animals to respective withdrawal animals following II-way ANOVA

$(p<0.01)$ administration in diazepam withdrawal animals as compared to respective control groups.

\subsubsection{Time spent in central boxes}

Figure $2 \mathrm{~b}$ explained the significant effects of days $(\mathrm{F}(1,55)=$ $193.279, p<0.10)$, days $\times$ drugs $(\mathrm{F}(3,55)=30.989, p<0.01)$, days $\times$ treatment $(\mathrm{F}(1,55)=50.528, p<0.25)$, drugs $(\mathrm{F}(3$, $55)=46.953, p<0.01)$, and treatment $(\mathrm{F}(1,55)=96.844, p$ $<0.10)$. Post hoc analysis determined increased time spent in agmatine-treated animals after the 1st $(p<0.05)$ and 7th $(p<$ $0.01)$ administration in water-pretreated controls while in withdrawal animals after the 7th $(p<0.01)$ administration when compared with water controls, respectively. Significant increase in time spent was observed after 1 week of agmatine $(p<0.01)$ administration in water-pretreated animals. Time spent decreased in diazepam withdrawal animals after the 7 th agmatine $(p<0.01)$ administration from respective untreated controls.

\subsection{Elevated plus maze test}

3.2.1 Entries in open arms

Figure 3a determined the significant effects of days ( $\mathrm{F}(1$, $55)=1608.240, p<0.05)$, days $\times$ drugs $(F(3,55)=$ $218.558, p<0.01)$, days $\times$ treatment $(\mathrm{F}(1,55)=150.551$, $p<0.10)$, drugs $(\mathrm{F}(3,55)=40.118, p<0.01)$, and treatment $(\mathrm{F}(1,55)=118.997, p<0.10)$. Entries in open

Table 2 Effects of agmatine administration on brain GABA and glutamate concentration in diazepam withdrawal rats

\begin{tabular}{|c|c|c|c|c|}
\hline & \multicolumn{2}{|l|}{ Water } & \multicolumn{2}{|l|}{ Diazepam } \\
\hline & Water & Agmatine & Water & Agmatine \\
\hline$\overline{\text { GABA }}$ & $18.3 \pm 2.7$ & $23.7 \pm 4.7$ & $5.6 \pm 1.1^{b}$ & $21.6 \pm 4.7^{a}$ \\
\hline Glutamate & $35.14 \pm 3.14$ & $43.04 \pm 1.42$ & $77.37 \pm 4.29^{b}$ & $53.94 \pm 3.92^{a, b}$ \\
\hline
\end{tabular}


arms increased after the 7th administration of agmatine $(p<0.01)$ in water- and diazepam-pretreated animals while entries increased after the 1 st $(p<0.01)$ administration of agmatine in diazepam withdrawal animals when compared with water-treated control. Increased number of entries were observed after the 7th day of agmatine $(p<0.01)$ administration from the 1st administration in both water- and diazepam-pretreated animals. Similarly, entries in open arms increased in water controls $(p<0.05)$ after a week in water-pretreated animals. Decreased entries were observed in water-treated animals after the 1 st $(p<0.05)$ and 7th $(p<0.01)$ administrations in diazepam withdrawal animals as compared to respective untreated controls.

\subsubsection{Time spent in open arms}

Data in Fig. 3b was analyzed by II-way ANOVA that explained the significant effects of treatment $(\mathrm{F}(1,55)=$ 46.416, $p<0.25)$ whereas, non-significant effects of days $(\mathrm{F}(1,55)=5.907)$, days $\times$ drugs $(\mathrm{F}(3,55)=1.886)$, days $\times$ treatment $(F(1,55)=2.752)$, and drugs $(F(3,55)=$ $2.212)$. Time spent decreased significantly in water controls after the 7th $(p<0.01)$ day of diazepam withdrawal group. Significant decrease in time spent was observed after the 1st and 7th $(p<0.05)$ agmatine administration in diazepam withdrawal animals as compared to waterpretreated controls.

\subsection{Withdrawal symptoms score}

Figure 4 determined the significant effects of days ( $F$ $(4,55)=15.981, p<0.01)$, days $\times$ drugs $(\mathrm{F}(12,55)=$ $3.775, p<0.05)$, days $\times$ treatment $(\mathrm{F}(4,55)=52.829$, $p<0.01)$, drugs $(\mathrm{F}(3,55)=49.306, p<0.01)$, and treatment $(\mathrm{F}(1,55)=82.148, p<0.10)$. Decreased withdrawal scores were observed in agmatine $(p<$ $0.01)$ treated animals post $168 \mathrm{~h}$ from controls in water-pretreated animals, whereas scores were decreased significantly in agmatine-treated animals after 12 and $48(p<0.05)$, and 96 and $168(p<0.01) \mathrm{h}$ of diazepam withdrawal. Reduced withdrawal symptoms were observed in both control and withdrawal groups post $168 \mathrm{~h}(p<0.01)$ of agmatine-treated animals when compared from the 1st administration. Whereas, withdrawal symptoms were observed higher in water controls post 12 and $96 \mathrm{~h}(p<0.05)$ and post $48 \mathrm{~h}(p<0.01)$ in withdrawal animals when compared with respective controls.

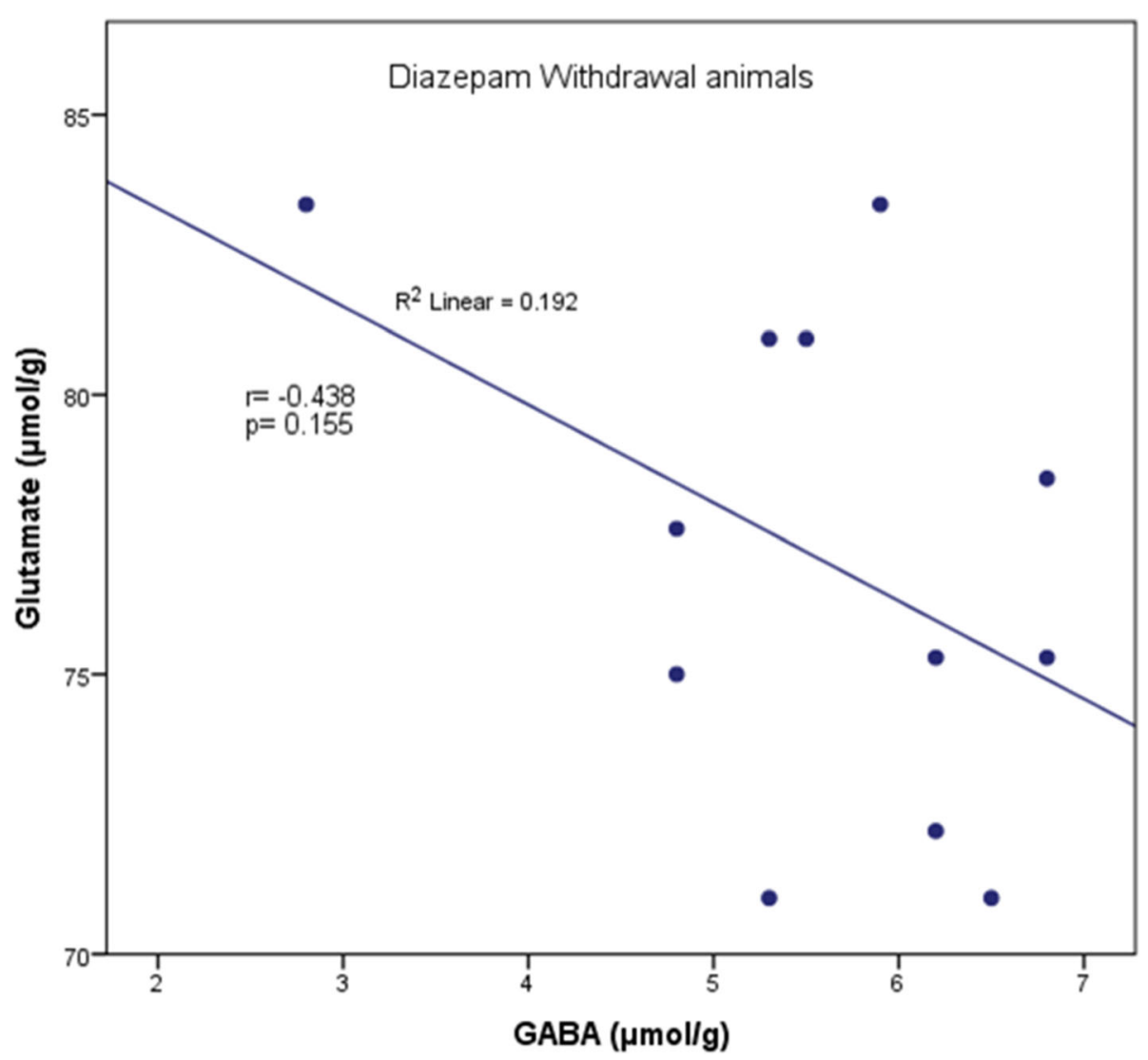

Fig. 7 Correlation between GABA and glutamate concentration in untreated diazepam withdrawal animals 


\subsection{Marbles buried test}

Data in Fig. 5 was analyzed by II-way ANOVA that explained the significant effects of days $(\mathrm{F}(1,55)=67.507$, $p<0.10)$, days $\times$ drugs $(\mathrm{F}(3,55)=92.509, p<0.01)$, days $\times$ treatment $(\mathrm{F}(1,55)=317.112, p<0.05)$, drugs $(\mathrm{F}$ $(3,55)=89.466, p<0.01)$, and treatment $(\mathrm{F}(1,55)=$ 355.504, $p<0.05)$. Post hoc analysis determined that agmatine significantly decreased percent marble burring after the 1st $(p<0.05)$ day in diazepam while after the 7th $(p<0.01)$ day of both water- and diazepampretreated animals. Similarly, a significant decrease in burying behavior was observed after the 7th $(p<0.01)$ day of agmatine administration from the 1st day in controls and withdrawal animals. In controls, increased percent of buried marbles were observed after the 7th $(p<$ $0.01)$ day in water-pretreated animals. However, percent decreased after 1 week of diazepam withdrawal in control animals. In diazepam withdrawal animals, percentage of buried marbles was increased in water- and agmatine-treated animals after the 1st $(p<0.01)$ day and in water-treated control after the 7th $(p<0.01)$ day as compared to water-pretreated control animals.

\subsection{Inverted screen test}

Figure 6 was determined the significant effects of days ( $F$ $(1,55)=206.023, \mathrm{p}<0.10)$, days $\times$ drugs $(\mathrm{F}(3,55)=$ $112.673, p<0.01)$, drugs $(\mathrm{F}(3,55)=216.470, p<0.01)$, and treatment $(\mathrm{F}(1,55)=92.915, p<0.10)$ whereas, non-significant effects of days $\times$ treatment $(F(1,55)=$ 3.885). Post hoc analysis determined a significant increase in latency after the 7 th $(p<0.01)$ administration of agmatine treatment in water-pretreated animals, while latency increased significantly after the 1st and 7th $(p<$ 0.01 ) administration of agmatine in diazepam withdrawal animals. Latency to fall decreased significantly in watertreated controls after the 1st $(p<0.01)$ and 7th $(p<$ $0.05)$ day in withdrawal animals. Similarly, decrease in latency was observed in agmatine-treated animals after the 7th $(p<0.05)$ administration withdrawal animals when compared with water-pretreated controls.

\subsection{Biochemical estimations}

Data given in Table 2 was analyzed by I-way ANOVA. Statistical analysis determined the significant effects of treatments on $\operatorname{GABA}(\mathrm{F}(5,66)=61.688, p<0.01)$ and

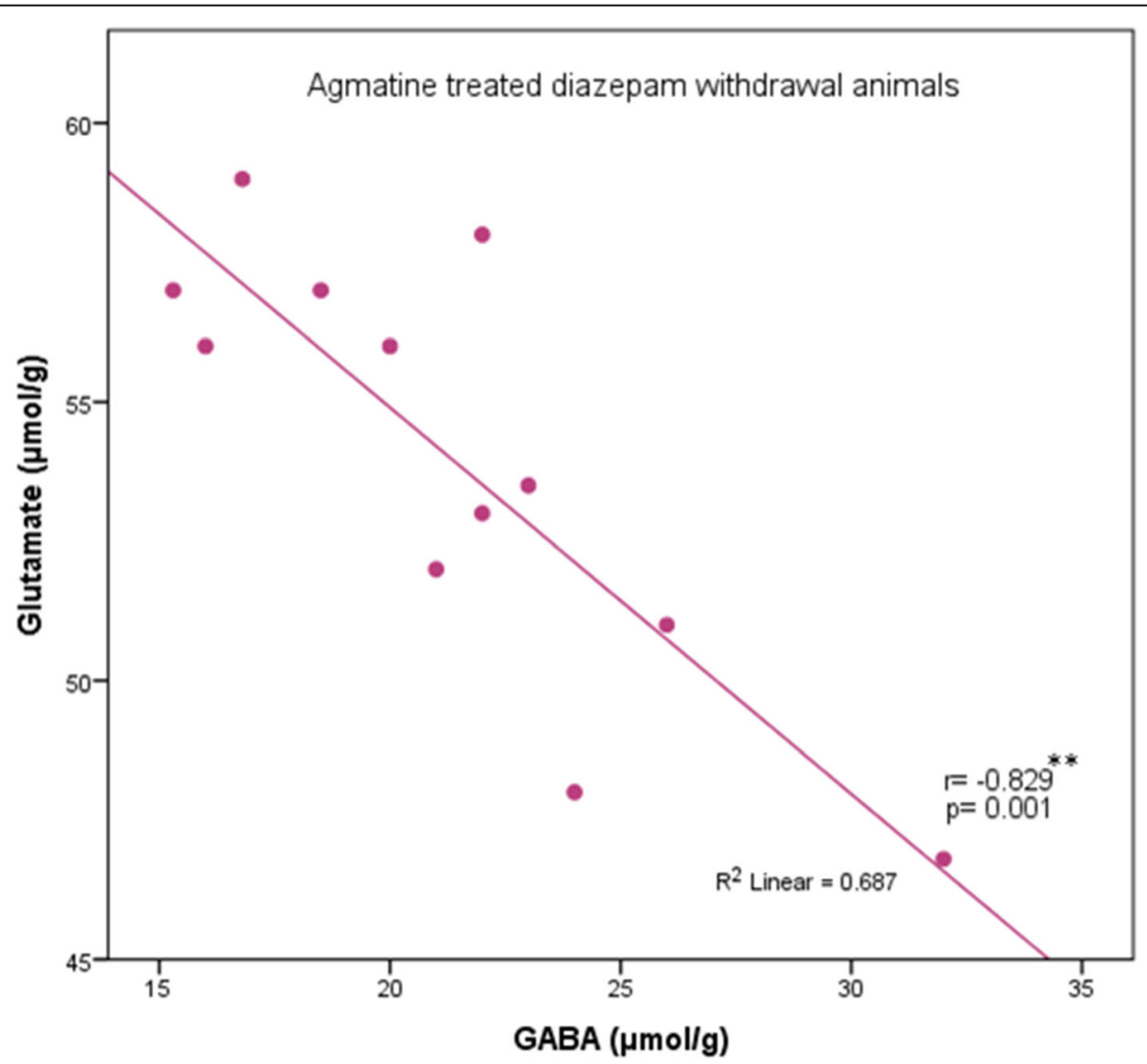

Fig. 8 Correlation between GABA and glutamate concentration in agmatine-treated diazepam withdrawal animals. Correlation is significant at ${ }^{*} p$ $<0.05,{ }^{* *} p<0.01$ level 
glutamate $(\mathrm{F}(5,66)=172.473, p<0.01)$ levels in diazepam withdrawal animals. Significant increased GABA $(p<$ 0.01 ) levels were observed in agmatine-treated withdrawal animals. However, concentration of glutamate decreased $(p<0.01)$ significantly in withdrawal rats treated with agmatine when compared with controls. GABA levels $(p<$ 0.01 ) decreased significantly in diazepam withdrawal rats compared with water-pretreated controls. While glutamate levels increased in both water $(p<0.01)$ and agmatine $(p<0.01)$-treated withdrawal animals.

\subsection{Pearson correlation test}

Correlation between GABA and glutamate in diazepam withdrawal animal was determined by Pearson correlation test. Figure 7 demonstrated a non-significant negative correlation was observed between GABA and glutamate in water-treated diazepam $(\mathrm{r}=-0.438, p>$ 0.05 ) withdrawal animals, whereas correlation between GABA and glutamate levels was exhibited in Fig. 8 that described a significant negative correlation between agmatine administered $\left(\mathrm{r}=-0.829^{* *}, p<0.01\right)$ diazepam withdrawal rats. A non-significant negative correlation was observed in Fig. 9 between GABA and withdrawal score in agmatine-treated $(\mathrm{r}=-0.448, p>$
0.05) withdrawal animals. Similarly, Fig. 10 determined non-significant positive correlation in agmatine-treated diazepam $(r=0.335, p>0.05)$ withdrawal animals.

\section{Discussion}

Discontinuation of benzodiazepine results in the appearance of withdrawal syndrome [30]. Tolerance and withdrawal are two manifestation of a single mechanism while withdrawal occurs when benzodiazepine counterbalancing is absent [3]. Present study was designed to study underline neurobiological mechanism of agmatine to attenuate benzodiazepine withdrawal syndrome. The study has also revealed physiological and behavioral alternations in withdrawal animals including anxiogenesis, motor skills, compulsion, and various other withdrawal symptoms.

GABA receptor alternation and neurotransmission affect the intoxicating and reinforcing properties of benzodiazepines [24]. Withdrawal symptoms initiate due to decreased GABAergic function and increased glutamatergic excitatory function. GABA-A receptors paly a fundamental role in benzodiazepines reward and withdrawal symptoms [24]. The present study describes an increase in withdrawal symptoms score in diazepam

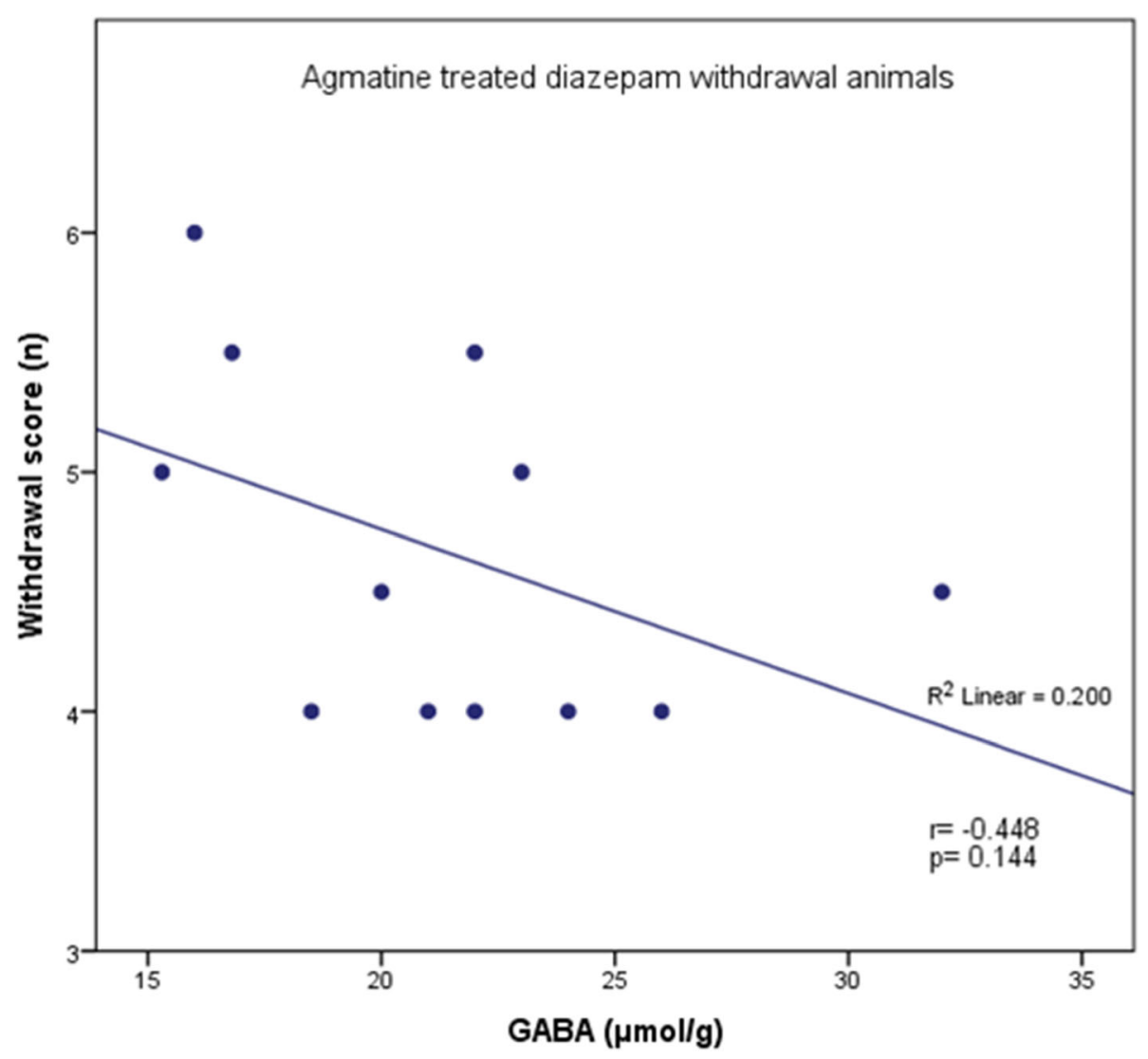

Fig. 9 Correlation between GABA levels and withdrawal score in agmatine-treated diazepam withdrawal animals 
withdrawal animals while these symptoms decreased significantly in agmatine-treated animals. A negative correlation between GABA and glutamate levels is also observed in diazepam withdrawal animals. Diazepam withdrawal is found to induce enhancement of GABAergic receptor inhibition and glutamatergic receptor excitation contributing to increased anxiety and seizures [3]. The study revealed a significant decline in withdrawal symptoms such as agitation, abnormal body posture, stereotype behaviors, vocalization, piloerection, tremors, and convulsions in agmatine-treated rats. Agmatine treatment significantly decreased withdrawal symptoms after the 2nd dose of $100 \mathrm{mg} / \mathrm{Kg}$ post diazepam withdrawal. Various studies have described therapeutic effects of agmatine in morphine dependence mechanism $[4,5]$, nicotine withdrawal and dependency $[14,21]$, and cocaine and methamphetamine dependency [18, 25]. The present study supports agmatine as a potent neuropharmacological active agent in benzodiazepine dependence mechanism. The study proposed that agmatine attenuates behaviors associated with diazepam withdrawal by antagonizing NMDA receptors leading to glutamate inhibition and upregulation of GABA-A receptor by acting on $\alpha 2$-adrenergic receptors.
Agmatine binds to $\alpha 2$-adrenoceptors [31] and blocks NMDA receptor [39]. These abilities of agmatine are considered potential mechanisms for reversing diazepam withdrawal syndrome. Binding abilities of agmatine to $\alpha 2$-adrenoceptors inhibited withdrawal syndrome similar to clonidine which produces same inhibitory effects in rats [28]. $\alpha 2$ receptor agonist stimulate release of GABA from astrocytes cells [16]. Present data suggests enhancement of GABA release by $\alpha 2$-adrenoceptors modulation and supports agmatine as a potential modulator in GABA receptor regulation. Anxiety is a common symptom of drug withdrawal $[20,26]$. Benzodiazepine cessation also results in the appearance of anxiety, sensory disturbances, and insomnia [30]. The effects of agmatine and diazepam withdrawal-induced anxiety were studied in open field, elevated plus maze, and marbles burying test. Study shows locomotion, rearing frequencies, and seizures assessed through open field are non-drastic and reliable method to evaluate withdrawal symptoms in rodents [9]. Open field test revealed improved locomotive and anxiolytic activities in agmatine-treated rats. Numbers of central and total box crosses were increased significantly along with

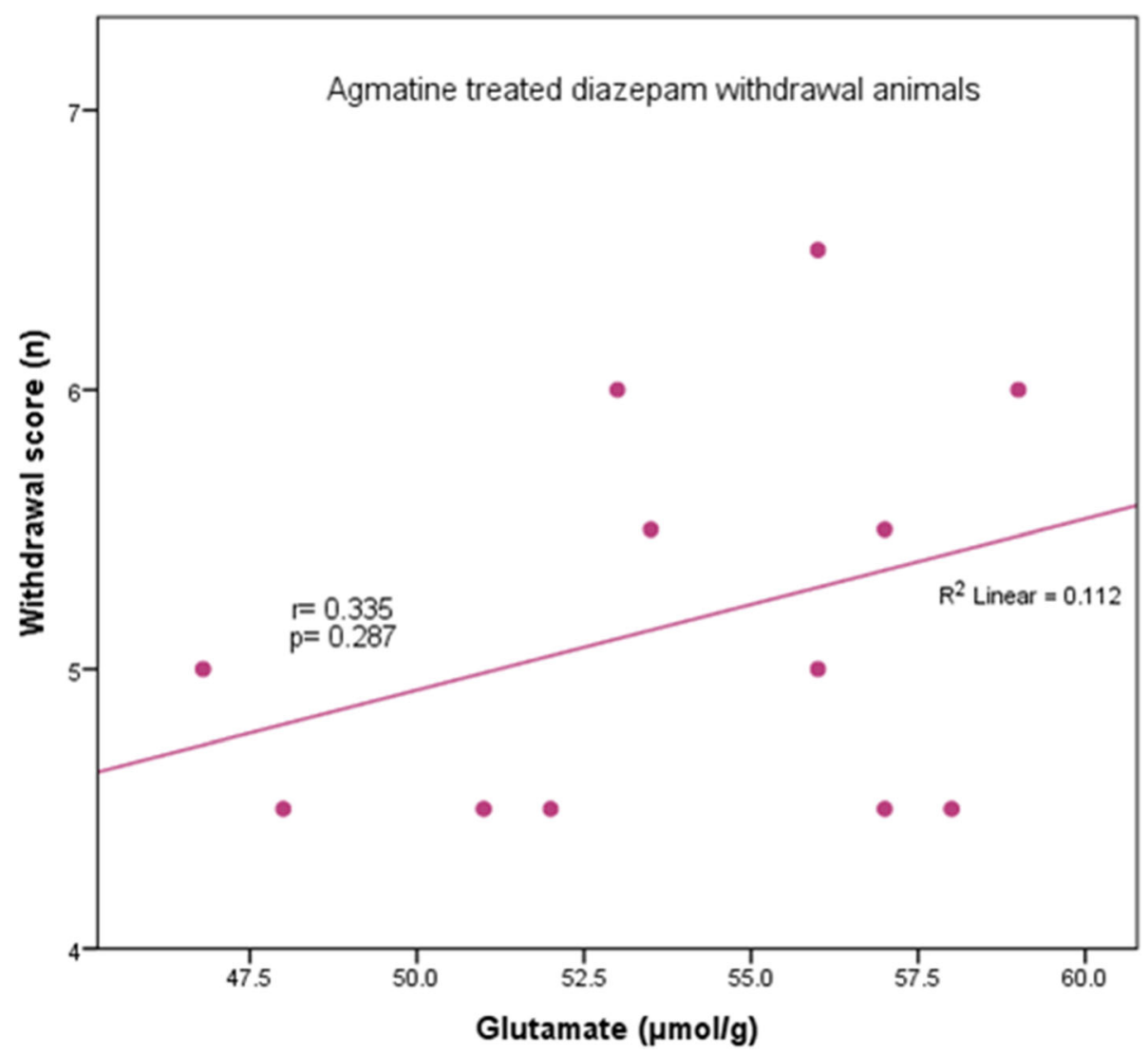

Fig. 10 Correlation between glutamate concentration and withdrawal score in agmatine-treated diazepam withdrawal animals 
time spent in central boxes in agmatine-treated withdrawal rats. Agmatine significantly produced anxiolytic behavior in rats by increasing central boxes time spent in withdrawal animals. Open field test and elevated plus maze are commonly chosen to evaluate potential changes in anxiety behavior induced by withdrawal of ethanol due to elevated anxiety behaviors reported after drug cessation (Hall and Zador, 1997 [17]. Present study revealed that animals having withdrawal symptoms demonstrated reduced number of entries and time spent in open arms of elevated plus maze. However, agmatine significantly increased number of entries and time spent in open arms in diazepam withdrawal animals. Present study determines significant therapeutic effects of agmatine in anxiety paradigms. These results confirm anxiolytic properties of agmatine in withdrawal syndrome. One of the anxiety disorders is obsessive-compulsive disorder which is often seen in alcohol withdrawal patients [10,33]. Marble burying behavior was previously witnessed in drug withdrawal animals to observe compulsive-like behavior [35]. Benzodiazepine withdrawal leads to brain hyperactivity due to reduction in GABA levels. Obsessive-compulsive symptoms developed and directly related to complete disappearance of diazepam [12]. Marble burying test was performed to assess compulsive behavior in diazepam withdrawal animals. Present study has shown a decrease in percent marbles buried in agmatine administered diazepam animals. Somatic signs of benzodiazepine withdrawal include tremors, body rigidity, wet dog shakes and loss of motor coordination, muscular pain, and stiffness $[8,13]$. Inverted screen test was used to evaluate effects of agmatine on muscular strength and reduction of tremors and convulsions. The data shows improved gripping abilities of withdrawal rats treated with agmatine confirming enhanced muscular strength. Ethanol and diazepam induced tremors and convulsion that weaken muscular strength and gripping abilities in withdrawal animals. Agmatine demonstrated a significant increase in latency to drop in inverted screen test. These results confirm agmatine as a potent polyamine for enhancing muscular strength and reducing withdrawal-induced tremors and convulsions.

Furthermore, the study has potential limitations. The animals selected were male and young while diazepam is widely prescribed to both male and female old age patient as antidepressant. Further studies are required to identify the role of agmatine in various regions of brain in animal model of diazepam withdrawal.

\section{Conclusion}

Present study revealed the potential mechanism of action of agmatine at NMDA receptor that may lead to modulation of GABA and glutamate levels during withdrawal syndrome. Moreover, agmatine has effectively attenuated benzodiazepine withdrawal symptoms including anxiety, irritability, agitation, compulsive behavior, mobility, and muscular strength.

\section{Abbreviations \\ NMDA: N-methyl-D-aspartate; GABA: Gamma aminobutyric acid; NOS: Nitrous oxide; NaCl: Sodium chloride; EPM: Elevated plus maze; AMPA: Alpha-amino- 3-hydroxy-5-methyl-4-isoxazole propionic acid; mTOR: Mechanistic target of rapamycin; eEF2: Eukaryotic translation elongation factor 2; BDNF: Brain- derived neurotrophic factor; EAAT1/2: Excitatory amino acid transporters 1/2; EAAT3: Excitatory amino acid transporters 3; GAD: Glutamate decarboxylase; VGluT: Vesicular glutamate transporter; ANOVA: Analysis of variance; p.o.: Per os (oral administration)}

\section{Acknowledgements}

Declared none.

\section{Authors' contributions}

The authors have read and approved the manuscript.

HR: Study concept and design. Data collection. Data analysis or interpretation. Writing the paper. HRa. Data collection. MF. Research

supervisor. The authors read and approved the final manuscript.

Funding

None.

Availability of data and materials

All relevant data are within the manuscript.

\section{Declarations}

\section{Ethics approval and consent to participate}

All experiments were approved by the Institutional Advanced Studies and Research Board (BASR/03367/Sc.) and performed in strict accordance with National Institute of Health Guide for Care and Use of Laboratory Animals (NIH Publication no. 85-23, revised 2011).

\section{Consent for publication}

Not applicable.

\section{Competing interests}

The authors declare that they have no competing interests.

Received: 14 January 2021 Accepted: 12 May 2021

Published online: 31 July 2021

\section{References}

1. Alachkar A, Brotchie J, Jones OT (2006) a2-Adrenoceptor-mediated modulation of the release of GABA and noradrenaline in the rat substantia nigra pars reticulata. Neurosci Lett 395(2):138-142 https://doi.org/10.1016/j. neulet.2005.10.069

2. Albelda N, Joel D (2012) Animal models of obsessive-compulsive disorder: exploring pharmacology and neural substrates. Neurosci Biobehav Rev 36(1):47-63 https://doi.org/10.1016/..neubiorev.2011.04.006

3. Allison C, Pratt JA (2003) Neuroadaptive processes in GABAergic and glutamatergic systems in benzodiazepine dependence. Pharmacol Ther 98(2):171-195 https://doi.org/10.1016/S0163-7258(03)00029-9

4. Aricioglu F, Means A, Regunathan S (2004) Effect of agmatine on the development of morphine dependence in rats: potential role of CAMP system. Eur J Pharmacol 504(3):191-197 https://doi.org/10.1016/j.ejphar.2 004.10.011

5. Aricioglu-Kartal F, Uzbay IT (1997) Inhibitory effect of agmatine on naloxone-precipitated abstinence syndrome in morphine dependent rats. Life Sci 61(18):1775-1781 https://doi.org/10.1016/S0024-3205(97)00801-1

6. Ashton $\mathrm{H}$ (1995) Protracted withdrawal from benzodiazepines: the postwithdrawal syndrome. Psychiatr Ann 25(3):174-179 https://doi.org/10.3928/ 0048-5713-19950301-11

7. Bernt E, Bergmeyer HU (1974) L-glutamate UV-assay with gutamate dehydrogenase and NAD. In: Methods of enzymatic analysis. Academic, pp 1704-1715 
8. Braconi S, Sidhpura N, Aujla H, Martin-Fardon R, Weiss F, Ciccocioppo R (2010) Revisiting intragastric ethanol intubation as a dependence induction method for studies of ethanol reward and motivation in rats. Alcohol Clin Exp Res 34(3):538-544 https://doi.org/10.1111/j.1530-0277.2009.01119.x

9. Capaz FR, Vanconcellos LE, De Moraes S, Neto JP (1981) The open field: a simple method to show ethanol withdrawal symptoms. Arch Int Pharmacodyn Ther 251(2):228-236

10. da Silva Lima AFB, Pechansky F, de Almeida Fleck MP, De Boni R (2005) Association between psychiatric symptoms and severity of alcohol dependence in a sample of Brazilian men. J Nerv Ment Dis 193(2):126-130 https://doi.org/10.1097/01.nmd.0000152818.38001.2C

11. De Boer SF, Koolhaas JM (2003) Defensive burying in rodents: ethology, neurobiology and psychopharmacology. Eur J Pharmacol 463(1-3):145-161 https://doi.org/10.1016/S0014-2999(03)01278-0

12. Drummond LM, Matthews HP (1988) Obsessive-compulsive disorder occurring as a complication in benzodiazepine withdrawal. J Nerv Ment Dis 176(11):688-691 https://doi.org/10.1097/00005053-198811000-00008

13. Economidou D, Cippitelli A, Stopponi S, Braconi S, Clementi S, Ubaldi M, Ciccocioppo R (2011) Activation of brain NOP receptors attenuates acute and protracted alcohol withdrawal symptoms in the rat. Alcohol Clin Exp Res 35(4):747-755 https://doi.org/10.1111/j.1530-0277.2010.01392.x

14. El-Sherbeeny NA, Nader MA, Attia GM, Ateyya H (2016) Agmatine protects rat liver from nicotine-induced hepatic damage via antioxidative, antiapoptotic, and antifibrotic pathways. Naunyn Schmiedeberg's Arch Pharmacol 389(12):1341-1351 https://doi.org/10.1007/s00210-016-1284-9

15. Gadotti VM, Tibola D, Paszcuk AF, Rodrigues ALS, Calixto JB, Santos AR (2006) Contribution of spinal glutamatergic receptors to the antinociception caused by agmatine in mice. Brain Res 1093(1):116-122 https://doi.org/10.1 016/j.brainres.2006.03.087

16. Gaidin SG, Zinchenko VP, Sergeev Al, Teplov IY, Mal'tseva VN, Kosenkov AM (2020) Activation of alpha-2 adrenergic receptors stimulates GABA release by astrocytes. Glia 68(6):1114-1130 https://doi.org/10.1002/glia.23763

17. Hall W, Zador D (1997) The alcohol withdrawal syndrome. Lancet 349(9069): 1897-1900

18. Kitanaka N, Kitanaka J, Hall FS, Uhl GR, Watabe K, Kubo H, Takemura M (2014) Agmatine attenuates methamphetamine-induced hyperlocomotion and stereotyped behavior in mice. Behav Pharmacol 25(2):158-165 https:// doi.org/10.1097/FBP.0000000000000030

19. Kondziella W (1964) A new method for the measurement of muscle relaxation in white mice. Arch Int Pharmacodyn Ther 152:277-284

20. Koob GF, Le Moal M (1997) Drug abuse: hedonic homeostatic dysregulation. Science 278(5335):52-58 https://doi.org/10.1126/science.278. 5335.52

21. Kotagale NR, Chopde CT, Umekar MJ, Taksande BG (2015) Chronic agmatine treatment prevents behavioral manifestations of nicotine withdrawal in mice. Eur J Pharmacol 754:190-198 https://doi.org/10.1016/j.ejphar.2015.02. 033

22. Li DP, Atnip LM, Chen SR, Pan HL (2005) Regulation of synaptic inputs to paraventricular-spinal output neurons by a2 adrenergic receptors. J Neurophysiol 93(1):393-402 https://doi.org/10.1152/jn.00564.2004

23. Lowe IP, Robins E, Eyerman GS (1958) The fluorimetric measurement of glutamic decarboxylase and its distribution in brain. J Neurochem 3(1):8-18 https://doi.org/10.1111/j.1471-4159.1958.tb12604.x

24. Malcolm RJ (2003) GABA systems, benzodiazepines, and substance dependence. J Clin Psychiatry 64:36-40

25. Morgan AD, Campbell UC, Fons RD, Carroll ME (2002) Effects of agmatine on the escalation of intravenous cocaine and fentanyl self-administration in rats. Pharmacol Biochem Behav 72(4):873-880 https://doi.org/10.1016/ S0091-3057(02)00774-8

26. Moy SS, Knapp DJ, Duncan GE, Breese GR (2000) Enhanced ultrasonic vocalization and Fos protein expression following ethanol withdrawal: effects of flumazenil. Psychopharmacology 152(2):208-215 https://doi.org/1 $0.1007 / \mathrm{s} 002130000507$

27. Murphy SM, Tyrer P (1988) The essence of benzodiazepine dependence. In: The psychopharmacology of addiction. Oxford University Press, Oxford, pp 157-167

28. Parale MP, Kulkarni SK (1986) Studies with \{a 2\}-adrenoceptor agonists and alcohol abstinence syndrome in rats. Psychopharmacology 88(2):237-239 https://doi.org/10.1007/BF00652247

29. Pellow S, File SE (1986) Anxiolytic and anxiogenic drug effects on exploratory activity in an elevated plus-maze: a novel test of anxiety in the rat. Pharmacol Biochem Behav 24(3):525-529 https://doi.org/10.1016/0091-3 057(86)90552-6

30. Petursson $\mathrm{H}$ (1994) The benzodiazepine withdrawal syndrome. Addiction 89(11):1455-1459 https://doi.org/10.1111/j.1360-0443.1994.tb03743.x

31. Piletz JE, Chikkala DN, Ernsberger P (1995) Comparison of the properties of agmatine and endogenous clonidine-displacing substance at imidazoline and alpha-2 adrenergic receptors. J Pharmacol Exp Ther 272(2):581-587

32. Roberts JC, Grocholski BM, Kitto KF, Fairbanks CA (2005) Pharmacodynamic and pharmacokinetic studies of agmatine after spinal administration in the mouse. J Pharmacol Exp Ther 314(3):1226-1233 https://doi.org/10.1124/ jpet.105.086173

33. Suzuki K, Muramatsu T, Takeda A, Shirakura K (2002) Co-occurrence of obsessive-compulsive personality traits in young and middle-aged Japanese alcohol-dependent men. Alcohol Clin Exp Res 26(8):1223-1227 https://doi. org/10.1111/j.1530-0277.2002.tb02659.x

34. Tahsili-Fahadan P, Yahyavi-Firouz-Abadi N, Khoshnoodi MA, MotieiLangroudi R, Tahaei SA, Ghahremani MH, Dehpour AR (2006) Agmatine potentiates morphine-induced conditioned place preference in mice: modulation by alpha (2)-adrenoceptors. Neuropsychopharmacology 31(8): 1722-1732 https://doi.org/10.1038/sj.npp.1300929

35. Umathe S, Bhutada P, Dixit P, Shende V (2008) Increased marble-burying behavior in ethanol-withdrawal state: modulation by gonadotropinreleasing hormone agonist. Eur J Pharmacol 587(1-3):175-180 https://doi. org/10.1016/j.ejphar.2008.03.035

36. Walsh RN, Cummins RA (1976) The open-field test: a critical review. Psychol Bull 83(3):482-504 https://doi.org/10.1037/0033-2909.83.3.482

37. Wang WP, lyo AH, Miguel-Hidalgo J, Regunathan S, Zhu MY (2006) Agmatine protects against cell damage induced by NMDA and glutamate in cultured hippocampal neurons. Brain Res 1084(1):210-216 https://doi. org/10.1016/j.brainres.2006.02.024

38. Williams D, Lewis J, McBride A (2001) A comparison of rating scales for the alcohol-withdrawal syndrome. Alcohol Alcohol 36(2):104-108 https://doi. org/10.1093/alcalc/36.2.104

39. Yang XC, Reis DJ (1999) Agmatine selectively blocks then-methyl-daspartate subclass of glutamate receptor channels in rat hippocampal neurons. J Pharmacol Exp Ther 288(2):544-549

\section{Publisher's Note}

Springer Nature remains neutral with regard to jurisdictional claims in published maps and institutional affiliations.

\section{Submit your manuscript to a SpringerOpen ${ }^{\circ}$ journal and benefit from:}

- Convenient online submission

- Rigorous peer review

- Open access: articles freely available online

High visibility within the field

- Retaining the copyright to your article

Submit your next manuscript at $>$ springeropen.com 